\title{
Consistent Changes in the Sea Ice Seasonal Cycle in Response to Global Warming
}

\author{
IAN EISENMAN \\ California Institute of Technology, Pasadena, California, and University of Washington, Seattle, Washington \\ TAPIO SCHNEIDER \\ California Institute of Technology, Pasadena, California \\ DAvid S. BATTISTI AND CECILIA M. Bitz \\ University of Washington, Seattle, Washington
}

(Manuscript received 3 September 2010, in final form 16 March 2011)

\begin{abstract}
The Northern Hemisphere sea ice cover has diminished rapidly in recent years and is projected to continue to diminish in the future. The year-to-year retreat of Northern Hemisphere sea ice extent is faster in summer than winter, which has been identified as one of the most striking features of satellite observations as well as of state-of-the-art climate model projections. This is typically understood to imply that the sea ice cover is most sensitive to climate forcing in summertime, and previous studies have explained this by calling on factors such as the surface albedo feedback. In the Southern Hemisphere, however, it is the wintertime sea ice extent that retreats fastest in climate model projections. Here, it is shown that the interhemispheric differences in the model projections can be attributed to differences in coastline geometry, which constrain where sea ice can occur. After accounting for coastline geometry, it is found that the sea ice changes simulated in both hemispheres in most climate models are consistent with sea ice retreat being fastest in winter in the absence of landmasses. These results demonstrate that, despite the widely differing rates of ice retreat among climate model projections, the seasonal structure of the sea ice retreat is robust among the models and is uniform in both hemispheres.
\end{abstract}

\section{Introduction}

The extent of sea ice covering the ocean in the high northern latitudes varies between about $7 \mathrm{Mm}^{2}$ at summer minimum and $16 \mathrm{Mm}^{2}$ at winter maximum in today's climate (with $1 \mathrm{Mm}^{2}=10^{6} \mathrm{~km}^{2}$ ). During recent decades, Arctic sea ice has been rapidly retreating. The year-to-year retreat of sea ice extent has been considerably more rapid at summer minimum than at winter maximum (e.g., Serreze et al. 2007), with an associated increase in the amplitude of the seasonal cycle (Figs. 1a and 2). The increased seasonal cycle amplitude of Arctic sea ice extent, or approximately equivalently the increase in the extent of first-year ice (Comiso 2002), typically

Corresponding author address: Ian Eisenman, California Institute of Technology, 1200 East California Blvd., Pasadena, CA 91125.

E-mail: ian@gps.caltech.edu features prominently in assessments of recent observed changes in the Arctic sea ice (e.g., Nghiem et al. 2007; Kwok et al. 2009; Perovich et al. 2009).

The observed changes can be compared with the global warming projections from state-of-the-art atmosphereocean general circulation models (GCMs) that were carried out for the Coupled Model Intercomparison Project phase 3 (CMIP3), the results of which were used for the Intergovernmental Panel on Climate Change Fourth Assessment Report (Solomon et al. 2007). GCM projections vary widely in terms of the rate of Arctic sea ice loss (Fig. 3a) and demonstrate considerable biases when compared with observed ice retreat in both hemispheres (Fig. 3b). This makes it difficult to obtain a reliable estimate for the time scale of future Arctic sea ice retreat (cf. DeWeaver 2007; Boe et al. 2009; Wang and Overland 2009). However, the seasonal cycle of Arctic sea ice extent is consistently amplified as the climate warms in most of the GCMs (Figs. 2a,b), which has been 

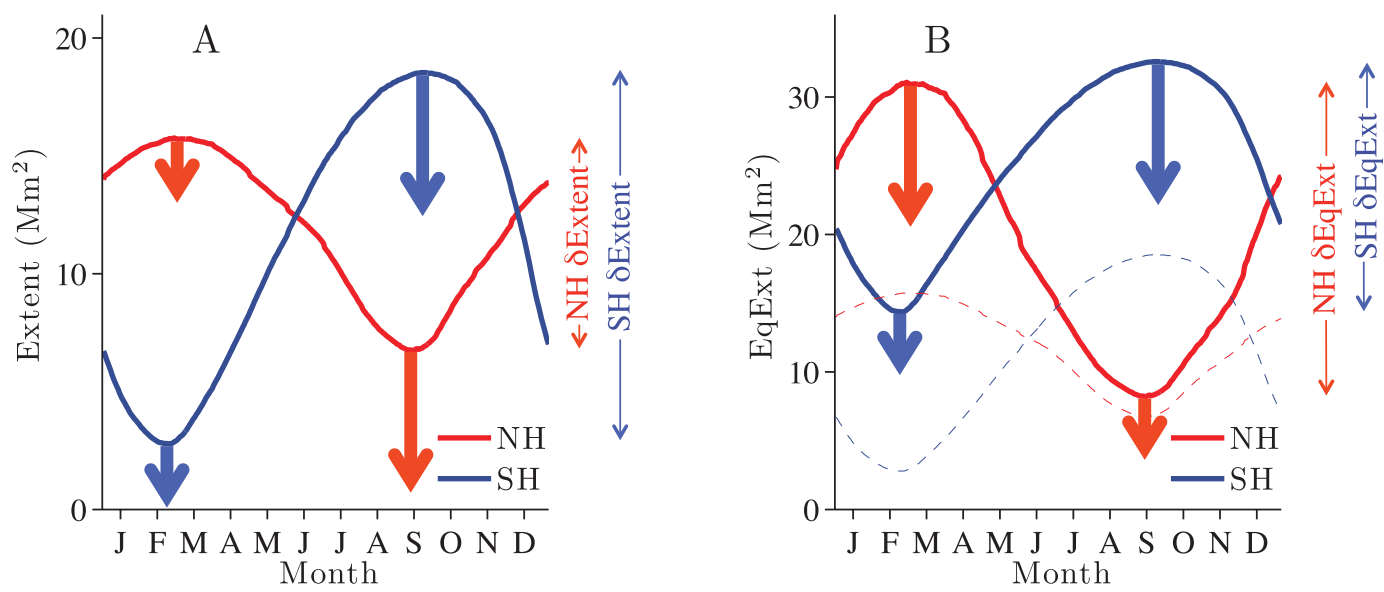

FIG. 1. Mean 1979-2000 seasonal cycle in sea ice cover with arrows schematically illustrating the difference between the year-to-year rate of change at summer minimum and winter maximum in both hemispheres. (a) Sea ice extent. (b) Sea ice equivalent extent (solid lines), which represents a rough approximation of what the ice extent would be in the absence of landmasses; sea ice extent (dashed lines) is included for comparison. Thin double-headed arrows identify the amplitude of the seasonal cycle. The lengths of the thick arrows are exaggerated to highlight the points discussed here.

identified as one of the most striking features of the Northern Hemisphere sea ice projections (Zhang and Walsh 2006). Hence, the GCM projections suggest that whatever is causing Arctic sea ice retreat to be fastest in summer may be expected to continue in the future.

In contrast to what is observed in the Northern Hemisphere, observations reveal very little long-term change in Southern Hemisphere sea ice extent, with the trend being toward a slight increase (Figs. 2d,e). Although the positive trend in Southern Hemisphere annual-mean sea ice extent is statistically significant (e.g., Comiso and Nishio 2008), the seasonal differences in the rate are small, and there is no significant change in the seasonal cycle amplitude (see appendix A). Hence, the observed sea ice cover in the Southern Hemisphere has not changed sufficiently to carry implications regarding how the ice extent seasonal cycle amplitude responds to climate change (Fig. 2f); therefore, it is not included in this analysis.

GCM projections, however, show Southern Hemisphere sea ice retreat that is fastest in winter (Figs. 2d,e), opposite to what occurs in the Northern Hemisphere (Fig. 1a). Although this feature can be readily seen in previously published results (Arzel et al. 2006; Solomon et al. 2007, their Fig. 10.13), scant discussion of it exists in the literature.

Most previously published physical mechanisms for changes in the seasonal cycle of sea ice extent have focused on observed changes in the Arctic. Summer minimum ice extent anomalies have been proposed to be preferentially amplified by seasonally dependent factors including the ice-albedo feedback (e.g., Lindsay and
Zhang 2005; Perovich et al. 2007), downward longwave radiative flux anomalies (Francis and Hunter 2007), and changes in ocean heat transport driven by the penetration of wind forcing through the sea ice cover (Shimada et al. 2006). It has also been suggested that thin ice reforms in winter wherever air is sufficiently cold but quickly melts during the following summer, causing the summer ice extent to be more sensitive than the winter ice extent to thermodynamic changes induced by increased greenhouse gases (e.g., Meier et al. 2005). However, explanations for the ice retreat being fastest in summer that rely on basic thermodynamic processes and feedbacks are inconsistent with the simulated ice retreat being fastest in winter in the Southern Hemisphere.

Alternatively, natural variability in atmospheric circulation has been proposed as an explanation for a substantial fraction of the observed loss of summer Arctic sea ice extent, with wind-driven ice advection during winter leading to thinner ice that is more easily melted during the following summer (Rigor et al. 2002). This mechanism was supported by observed correlations during the early and mid-1990s, and an associated longerterm reduction in the age of the ice cover was suggested to explain the continued ice retreat thereafter despite the sign of the correlations reversing (Rigor and Wallace 2004). More recently, correlations with a $925-\mathrm{hPa}$ wind index have been suggested to explain a significant fraction of the observed trend in minimum sea ice extent in summer (Ogi et al. 2010). Explanations for the ice retreat being fastest in summer that rely on natural variability in wind forcing, however, are at odds with the fact that the seasonal cycle amplitude of Northern Hemisphere sea ice 

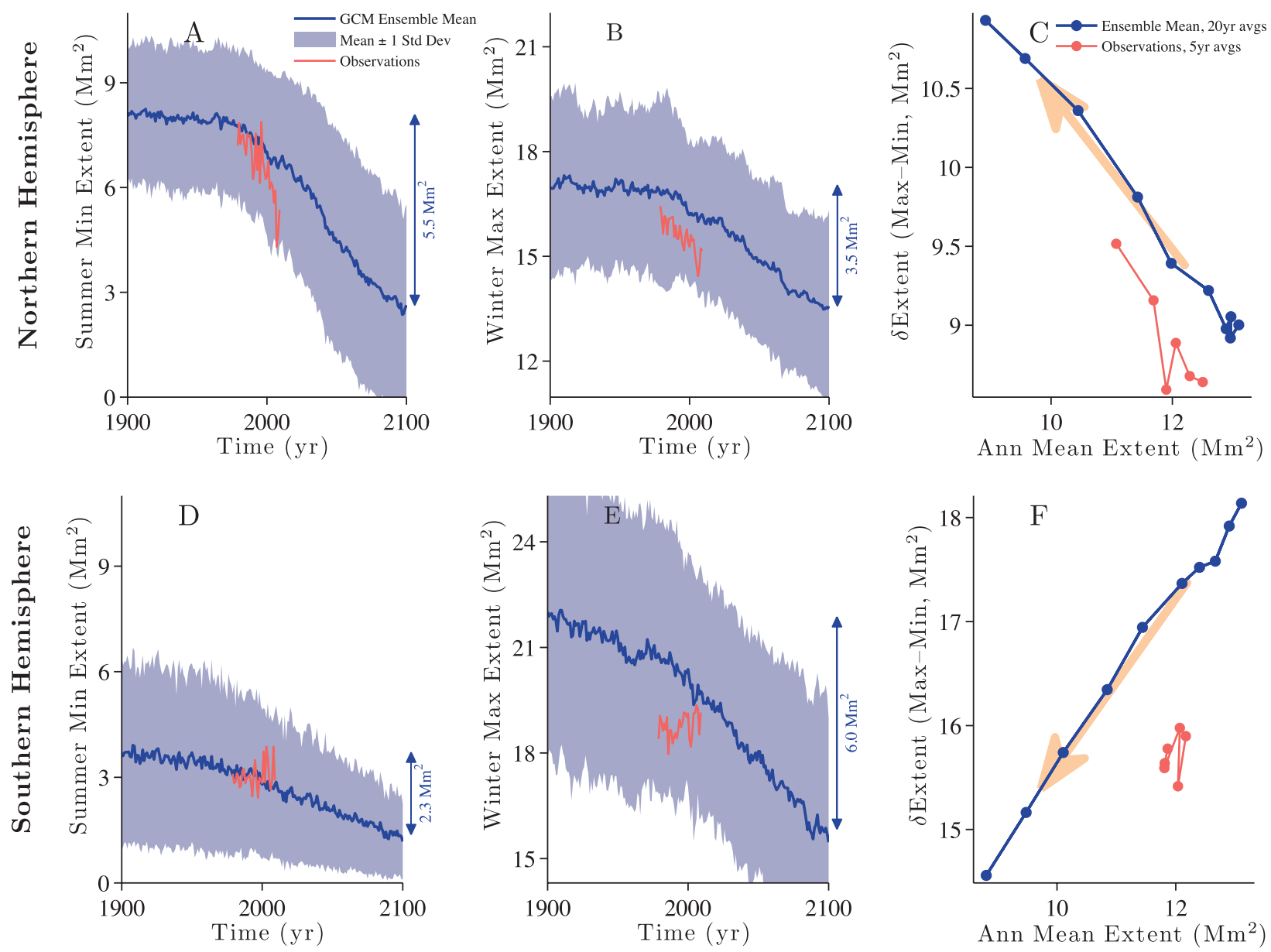

FIG. 2. Observed and simulated changes in sea ice extent in both hemispheres. The Northern Hemisphere (a) summer minimum and (b) winter maximum ice extent are plotted based on monthly-mean satellite-derived observations (see appendix A) and simulations from 21 coupled atmosphere-ocean GCMs (see appendix B). (c) The seasonal cycle amplitude is plotted as a function of the annual-mean ice extent, with 20-yr averages taken of the 1900-2100 GCM ensemble mean and 5-yr averages taken of the 1979-2009 observations. A thick arrow shows the direction of time evolution. (d)-(f) As in (a)-(c), but for the Southern Hemisphere. The simulated change in the amplitude of the ice extent seasonal cycle in the Southern Hemisphere shown in (f) is opposite to that in the Northern Hemisphere shown in (c). The vertical scales in (a),(b),(d),(e) are all identical. Note that most of the GCMs do not get seasonally ice free in either hemisphere during the simulation period.

extent increases during the entire twenty-first century in GCM simulations.

Changes in the seasonal cycle of sea ice extent in both hemispheres are summarized schematically in Fig. 1a. Because of the vast differences in the rate of retreat among GCM simulations (Fig. 3a), we consider a coordinate system here that does not depend on rate: we ask how the ice extent seasonal cycle amplitude changes as the annual-mean ice edge migrates poleward, regardless of the rate at which the annual-mean ice edge evolves. In Figs. $2 c$ and 2f, the amplitude of the seasonal cycle of sea ice extent in each hemisphere is plotted versus the annual-mean ice extent. As the annual-mean sea ice edge migrates poleward, the observed and simulated seasonal cycles of sea ice extent increase in the
Northern Hemisphere (Fig. 2c), whereas the seasonal cycle of simulated sea ice extent decreases in the Southern Hemisphere (Fig. 2f).

This study examines why the response to global warming of the seasonal cycle in sea ice extent is opposite between the two hemispheres in GCM projections. The GCMs are expected to encapsulate the zeroth-order processes governing the retreat of sea ice in the real world. These processes may be modified in the real world by processes that are not included or are poorly parameterized in GCMs, which can give rise to substantial model limitations, as illustrated in Fig. 3. For example, all of the models simulate a loss of Southern Hemisphere sea ice as the climate warms, whereas the observed Southern Hemisphere sea ice extent has increased in recent decades. 

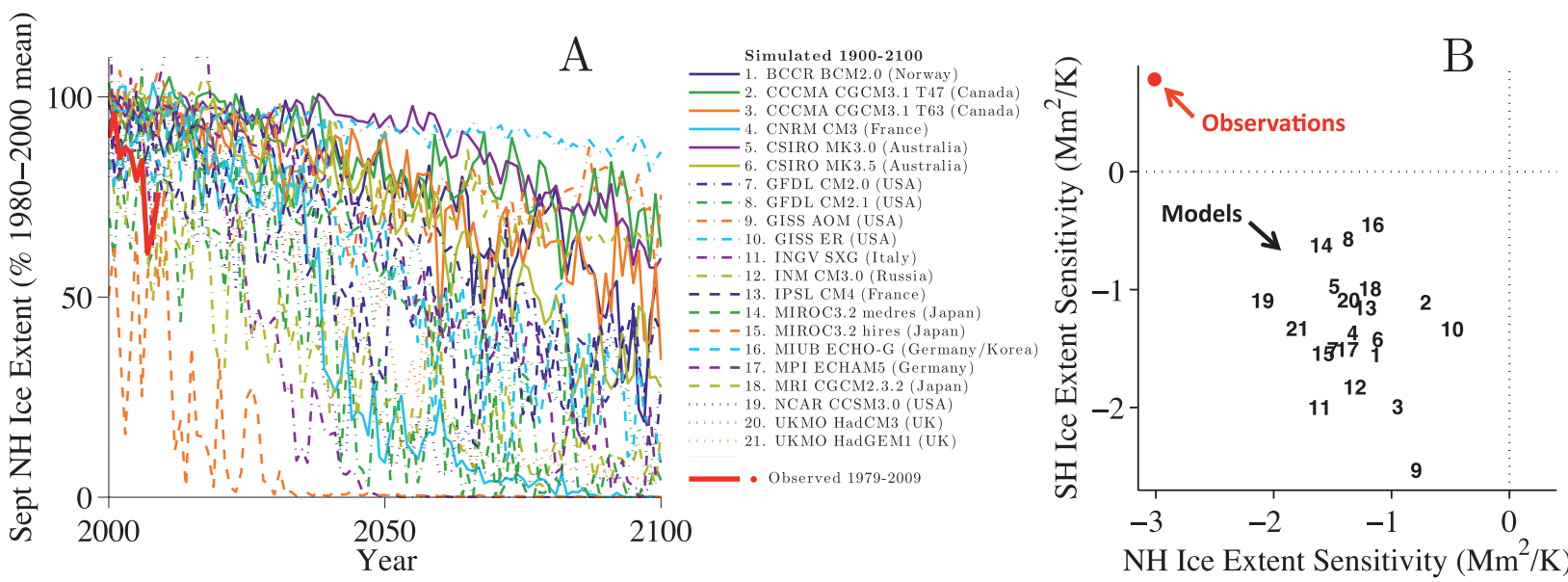

FIG. 3. Differences among the GCM projections of the rate of Arctic sea ice loss. (a) Timeline toward seasonally ice-free Arctic Ocean conditions indicated by Northern Hemisphere September sea ice extent during the twenty-first century scaled by the 1980-2000 mean September value for each model. In the ensemble mean, $32 \%$ of the September sea ice cover remains at the end of the century, but projections vary widely among the GCMs from one model retaining more than $85 \%$ of the ice cover to four models retaining less than $1 \%$. (b) Sea ice extent sensitivity, defined as the annual-mean change in hemispheric ice extent per change in global-mean temperature (Winton 2011), in both hemispheres in models and in observations (see appendix C).

Nonetheless, understanding the zeroth-order processes captured by the models is a necessary prerequisite to understanding the full physics of the real world. We focus here on the degree to which the underlying processes can give rise to responses that are robust among the GCMs.

\section{Effect of landmass distribution}

The differences in sea ice between the two hemispheres have been attributed to a variety of factors. Factors frequently discussed include hemispheric differences in the partitioning between first-year and multiyear components of the ice cover, differences in the strength of vertical stratification (there is a pronounced cold halocline in the Arctic but not in the Antarctic), differences in the atmospheric and oceanic circulation including the strong Antarctic Circumpolar Current, and differences in sea ice drift velocities. In addition, because snow accumulation rates are typically large on Southern Hemisphere sea ice, much of the growth occurs at the upper surface of the ice due to flooding under the weight of snow (Petrich and Eicken 2010), whereas sea ice in the Northern Hemisphere grows primarily through congelation at the ice-ocean interface. However, we will argue that the most important differences between the hemispheres arise because of the different configurations of continents, which constrain where sea ice can occur.

In the Northern Hemisphere, there is little land poleward of $75^{\circ} \mathrm{N}$, but extensive land south of this rims the Arctic Ocean (Fig. 4a). As a result, the equatorward edge of the sea ice cover is obstructed by land throughout the year except near the time of summer minimum ice extent. In the Southern Hemisphere, by contrast, the Antarctic continent extends from the pole to about $70^{\circ} \mathrm{S}$ but there is little land equatorward of this in the latitudes spanning the Southern Ocean (Fig. 4c). Hence the equatorward edge of the Southern Hemisphere sea ice cover rarely touches land.

Because sea ice is obstructed by landmasses, the shape of the Northern Hemisphere coastline causes changes in the sea ice edge latitude to have a muted effect on sea ice extent during much of the year (Fig. 4a). In Eisenman (2010), it was proposed that seasonal asymmetries in Arctic sea ice extent evolution ranging from the structure of the seasonal cycle to the unprecedented loss in September 2007 can be explained in terms of this muting. Here, we follow that work's definition of "equivalent extent" as the total land plus ocean surface area poleward of the zonal-mean latitude of the transition from sea ice to open water. The equivalent extent can be approximately visualized by drawing a straight line between the sea ice edge on either side of each landmass and filling in the region poleward of this line with sea ice. This provides a rough approximation of what the sea ice extent might be if all the land were removed.

The equivalent extent is proportional to the sine of the zonal-mean ice edge latitude (Eisenman 2010). In this work we focus on the equivalent extent, rather than on the zonal-mean ice edge latitude, to facilitate comparison with sea ice extent in the Southern Hemisphere, where the equatorward edge of the sea ice cover evolves in 
a nearly land-free geography. The changes in GCM ensemble-mean summer minimum and winter maximum ice cover during 1900-2100 are schematically illustrated in Fig. 4a, where circles are drawn with radii proportional to the colatitude of the simulated zonalmean sea ice edge. The decrease in ice extent, indicated by the white area between solid and dashed lines, is largest in summer. Wintertime changes in the ice edge have a considerably larger effect on equivalent extent than on extent, however, and the decrease in equivalent extent, indicated by the white plus gray area between solid and dashed lines, is largest in winter. Note that although the observed sea ice edge evolved at an approximately annual-constant rate during recent decades (Eisenman 2010), the wider range of climates explored in the GCM projections do not maintain this feature, as can be seen by comparing the radial distance between the solid and dashed lines in Fig. 4a.

We compute the sea ice equivalent extent from the sea ice extent using a two-step process. First, the latitude characterizing the sea ice edge is approximated by finding the latitude that has an ocean area poleward of it equal to the ice extent (arrows pointing right in Figs. 4b,d). Next, the equivalent extent is computed as the total land plus ocean area poleward of this latitude (arrows pointing left in Figs. 4b,d). Hence, in the limit of small changes in the ice cover, the change in ice extent is equal to the change in equivalent extent scaled by the zonal-mean ocean fraction (i.e., 1 - land fraction) at the latitude characterizing the sea ice edge. This calculation is carried out for the ice extent time series from observations and GCMs in both hemispheres, with the transfer function being computed separately from the land masks in each GCM (see appendix B) and in the observed fields (see appendix A).

\section{Results}

In the Northern Hemisphere, the summer minimum equivalent extent is similar to the summer minimum extent (Fig. 1b). Because the wintertime sea ice edge resides at a latitude with a large land fraction, however, the winter maximum equivalent extent is considerably larger (Fig. 1b) and retreats faster (Fig. 5b vs Fig. 2b) than the winter maximum extent. As expected from the cartoon in Fig. 4a, this influence of land is sufficient to cause the seasonal structure of the Northern Hemisphere sea ice retreat to be reversed: in contrast to the extent, the amplitude of the equivalent extent seasonal cycle decreases as the ice edge moves poleward in both observations and GCMs (Fig. 5c).

In the Southern Hemisphere, the equivalent extent (Figs. 5d,e) evolves similarly to the extent (Figs. 2d,e) with the addition of a constant equal to the area of the
Antarctic continent (Fig. 1b). Changes in the summer minimum equivalent extent (Fig. 5d) are somewhat enhanced compared with extent changes (Fig. 2d) because of the equatorward sea ice edge touching the Antarctic coastline (Fig. 4c), but the summer minimum equivalent extent still retreats more slowly than the winter maximum equivalent extent. Hence, after accounting for the muting effect of landmasses on sea ice extent changes, the seasonal cycle in equivalent extent decreases in both hemispheres as the ice edge migrates poleward (Figs. 5c,f; Fig. 1b).

The decreasing amplitude of the equivalent extent seasonal cycle in response to global warming occurs not only in the ensemble mean in both hemispheres (Figs. 5c,f) but also in most individual GCMs. In Fig. 6, the change during 1900-2100 in the amplitude of the equivalent extent seasonal cycle in each of the $21 \mathrm{GCMs}$ is plotted. That all points lie to the left of the origin indicates that all GCMs simulate a loss of annual-mean ice cover in both hemispheres in response to increased greenhouse gases. More striking is the feature that most points lie below the origin, indicating that most GCMs simulate a reduction in the sea ice equivalent extent seasonal cycle in both hemispheres. The bunching of points near a diagonal line indicates that, although they do not agree on the amount of ice retreat (wide spread in horizontal coordinates), the models do largely agree that the more the annual-mean ice cover diminishes (farther to left in Fig. 6), the smaller the equivalent extent seasonal cycle becomes (farther down in Fig. 6). The agreement among the models on this point is in stark contrast with their projections for the timeline of sea ice changes (Fig. 3a). The central message of Fig. 6 is that the seasonal cycle in sea ice equivalent extent diminishes in response to global warming in both hemispheres in most models (i.e., most points lie in the lower-left quadrant of the plot).

\section{Discussion}

These results allow a comparison between GCM simulations and observations. As has been noted previously (Stroeve et al. 2007; Winton 2011), the observed retreat of Northern Hemisphere sea ice extent is faster than the retreat in most GCM projections (Fig. 3a), and this discrepancy appears similarly in equivalent extent (cf. Fig. 5a). GCMs show an opposite bias in the Southern Hemisphere: whereas the observed Southern Hemisphere sea ice cover has expanded slightly, the models simulate a reduction in sea ice extent in the Southern Hemisphere that is similar to that in the Northern Hemisphere (Fig. 3b). The increase in observed Southern Hemisphere sea ice cover during recent decades may be related to stratospheric 

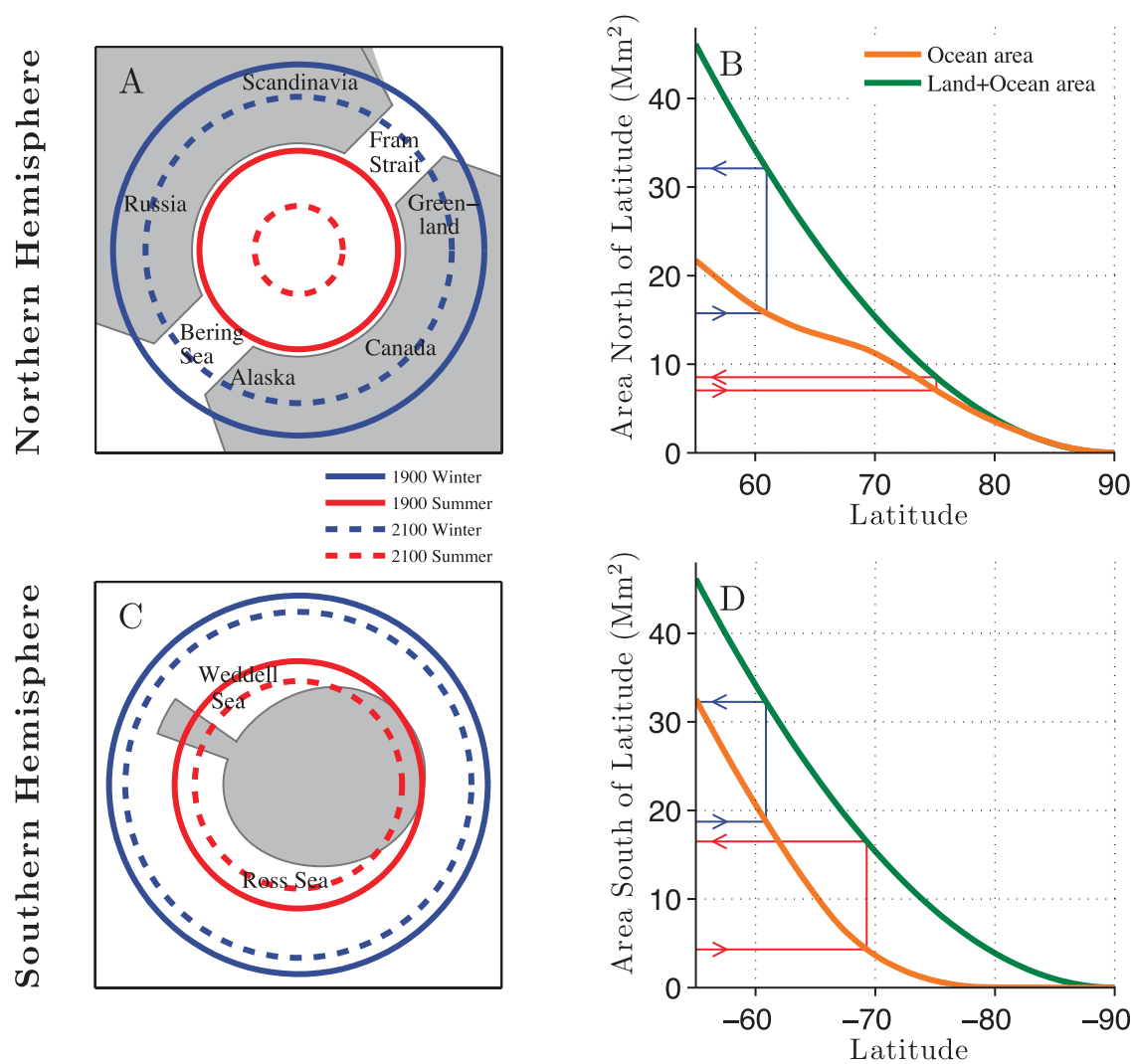

FIG. 4. Cartoon of landmass distributions in both hemispheres and schematic illustrating the calculation of sea ice equivalent extent from extent. (a) Cartoon of Northern Hemisphere geography, with gray indicating land and white indicating ocean. The latitude of the sea ice edge associated with summer minimum (red) and winter maximum (blue) ice cover at the beginning (solid circles) and end (dashed circles) of the simulated period is included based on the ensemble-mean ice edge latitude during 1900-20 and 2080-2100. The total white area enclosed within a given ice edge line indicates the ice extent, and the total white plus gray area enclosed within the line indicates the equivalent extent. (b) Mapping function used to calculate the sea ice equivalent extent from the extent. The blue line indicates the mapping of a typical Northern Hemisphere winter maximum ice extent to equivalent extent. Beginning with the ice extent (lower intersect of blue line with vertical axis), the latitude with area poleward of it equal to the extent is computed (intersect between blue and orange lines). Next, the total land plus ocean area poleward of this latitude is identified as the equivalent extent (intersect of blue and green lines). The red line indicates the mapping for a typical summer minimum ice extent, illustrating that the difference between equivalent extent and extent is considerably larger at winter maximum than at summer minimum. (c),(d) As in (a) and (b), but for the Southern Hemisphere. Here, the difference between extent and equivalent extent is similar at winter maximum (blue line) and at summer minimum (red line).

ozone depletion (Turner et al. 2009), which is not included in many of the GCM simulations considered here and may not be represented with sufficient accuracy in the GCMs that do include it (Son et al. 2008).

The seasonal structure of the equivalent extent retreat, however, shows better agreement between GCMs and observations in the Northern Hemisphere: the mean slopes of the red and blue curves in Fig. $5 \mathrm{c}$ differ by only $4 \%$. Note that the red and blue curves are vertically displaced from each other in Fig. 5 c by about $10 \%$. Such a comparison cannot be made in the Southern Hemisphere because the observed sea ice cover has not changed sufficiently to agree or disagree with the GCM response in Fig. 5f.

Discussions that compare sea ice in the two hemispheres typically find more differences than similarities (e.g., Dieckmann and Hellmer 2010). In Fig. 2a, the seasonal cycle in sea ice extent is considerably larger in the Southern Hemisphere than in the Northern Hemisphere, with summer and winter extremes both being outside the 

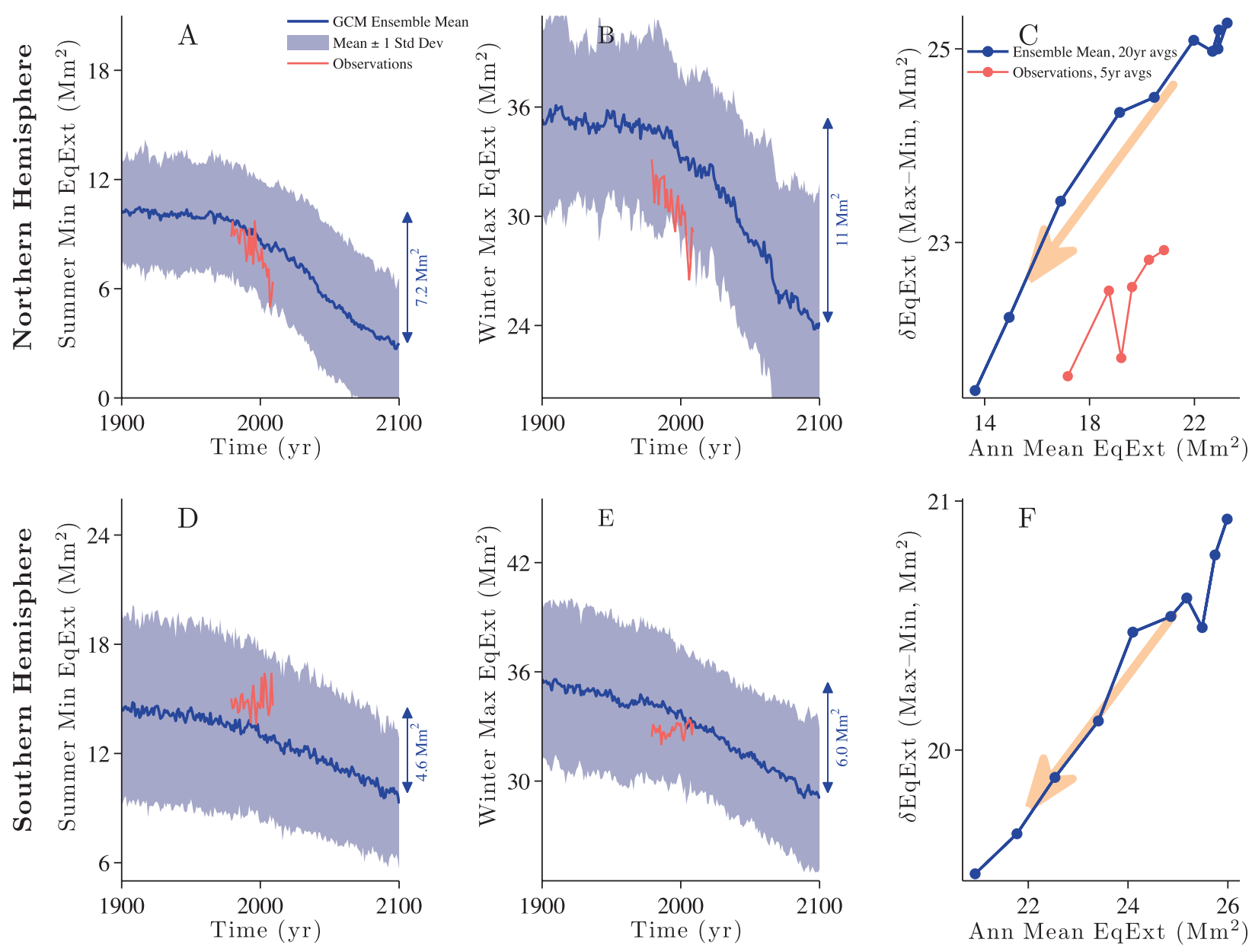

FIG. 5. As in Fig. 2, but for observed and simulated changes in sea ice equivalent extent in both hemispheres. In contrast to the sea ice extent, the sea ice equivalent extent seasonal cycle responds to global warming similarly in both hemispheres, as shown in (c) and (f). Note that the observed equivalent extent change in the Southern Hemisphere clusters near the point $(26,18)$ in (f) and therefore is not shown in the plotted range.

Northern Hemisphere seasonal range. This is associated with a more seasonal ice cover in the Southern Hemisphere than in the Northern Hemisphere. After we account for land, however, the seasonal cycles in the two hemispheres become more similar (Fig. 5). The winter maximum equivalent extent is nearly identical in the two hemispheres in simulations of the twentieth century, although the ice edge is farther poleward at summer minimum in the Northern Hemisphere than in the Southern Hemisphere.

The agreement between the two hemispheres is not only qualitative but is also quantitative. In Fig. $5 \mathrm{c}$ (Northern Hemisphere), the slope of the seasonal cycle amplitude versus annual-mean equivalent extent evolution is 0.4 , and in Fig. $5 \mathrm{f}$ (Southern Hemisphere) the slope is relatively similar at 0.3. Similarly, in Fig. 6, the distributions for both hemispheres are near to each other and both seem to fall near the same diagonal line.
In addition to illuminating the similarities between the sea ice evolutions in the two hemispheres, the equivalent extent may be a useful metric for comparing models because it addresses differences in model coastlines. Total sea ice cover in GCM simulations is typically compared in terms of ice extent (e.g., Zhang and Walsh 2006). There are considerable intermodel differences, however, in the land masks associated with the sea ice concentrations (i.e., fractional sea ice cover) in the CMIP3 archive. Grid boxes with land fractions between 0 and 1 are treated as land in some models but as ocean in others, and ice shelves are treated as land glaciers in some models but as sea ice in others. This causes the ocean area poleward of $70^{\circ}$, for example, to vary by more than $1 \mathrm{Mm}^{2}$ among the models, with an intermodel standard deviation of $0.9 \mathrm{Mm}^{2}$ in the Northern Hemisphere and $0.4 \mathrm{Mm}^{2}$ in the Southern Hemisphere. In other words, two GCMs may simulate Northern Hemisphere sea ice extents that differ by $1 \mathrm{Mm}^{2}$ 


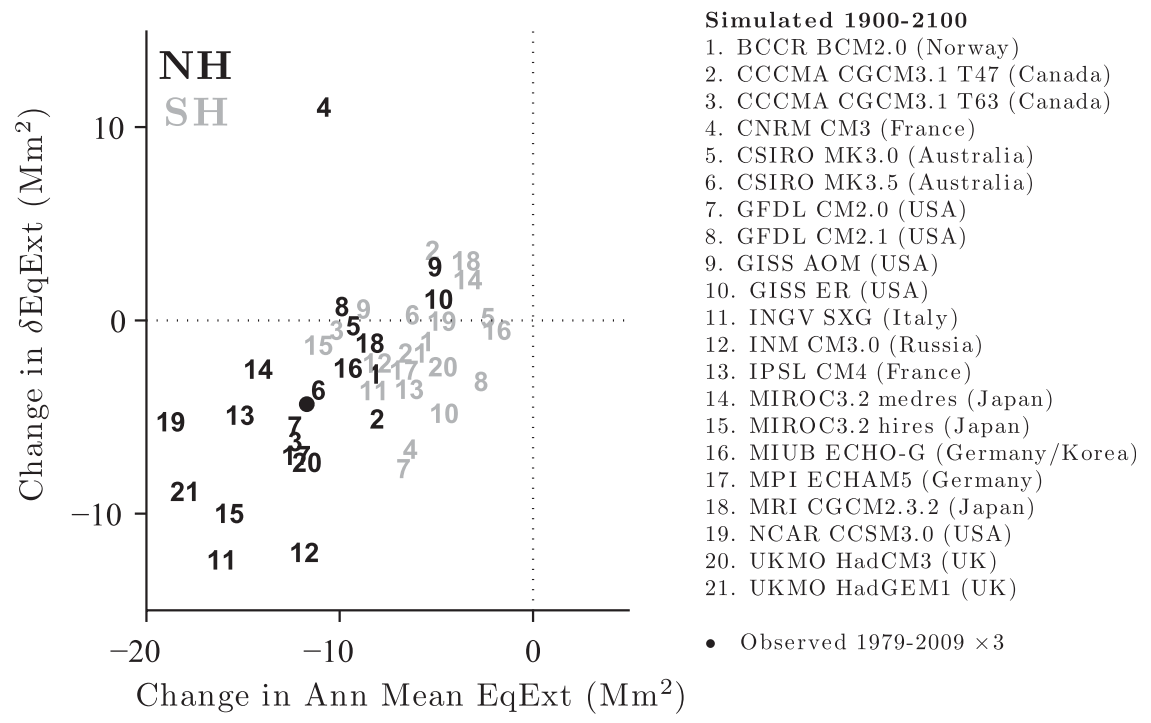

FIG. 6. Robustness among models. The change in the equivalent extent seasonal cycle amplitude during 1900-2100 in each GCM is plotted vs the change in annual-mean equivalent extent for the Northern Hemisphere (black) and the Southern Hemisphere (gray). Vertical and horizontal coordinates represent the vertical and horizontal displacements in Figs. 5c and $5 \mathrm{f}$ evaluated separately for each model. The observed Northern Hemisphere change during the shorter 31-yr period is included in the figure after being scaled by a factor of 3 (this factor is chosen to make the change in observed annual-mean equivalent extent approximately equal to the GCM ensemble mean). Changes during 1900-2100 are computed by multiplying by 2 the difference between the temporal mean during the first and last $100 \mathrm{yr}$; changes during 19792009 are computed similarly using the first and last $15 \mathrm{yr}$.

when both are identically simulating a sea ice cover that extends to $70^{\circ} \mathrm{N}$. These effects of land mask differences are naturally addressed when using sea ice equivalent extent.

In this analysis, we have followed the standard convention of defining ice extent as the area of grid boxes with sea ice concentration of at least $15 \%$. For a given sea ice cover, this definition depends on grid resolution. The sea ice concentration grids for the GCM data in the CMIP3 archive typically have resolutions on the order of $50-100 \mathrm{~km}$, whereas the observed sea ice extent is calculated using a nominally $25-\mathrm{km}$ grid. Sea ice area, defined as the sum of gridbox areas scaled by the ice concentration in each box, is independent of resolution, but it is more prone to systematic errors in satellitederived observations (e.g., Parkinson and Cavalieri 2008). Using sea ice area instead of extent, and hence calculating a sea ice equivalent area, does not qualitatively influence the GCM results presented here.

Some GCMs become seasonally ice free during the 1900-2100 simulation period. This leads to winter ice cover retreating faster than summer ice cover after the latter reaches zero (cf. Fig. 1). In Fig. 7a, the results of Fig. 6 are repeated for each hemisphere excluding all models that simulate less than $0.1 \mathrm{Mm}^{2}$ of sea ice extent in that hemisphere at any point during 1900-2100. Comparison of the two figures demonstrates that this effect does not qualitatively affect the results presented in Fig. 6.

The physical mechanism causing sea ice equivalent extent to decrease more rapidly in winter than in summer is expected to differ from previously proposed mechanisms since the latter were aimed at explaining why Northern Hemisphere sea ice retreat is fastest in summer. Several hints regarding the cause of the changes in the sea ice seasonal cycle can be gleaned from the GCM simulations. First, horizontal ice motion and rheology are included in all but one of the GCMs. The Institute of Numerical Mathematics Coupled Model version 3.0 (INM-CM3.0; labeled "12" in Fig. 6), however, simulates the sea ice as motionless. That this is not an outlier of the distribution in both hemispheres in Fig. 6 is evidence that horizontal ice motion is not a primary factor. Second, there is considerably more simulated snowfall on the sea ice in the Southern Hemisphere than in the Northern Hemisphere (Solomon et al. 2007, their Fig. 8.5), which is typically associated with the difference in land fraction immediately equatorward of the sea ice cover. Additionally, the ocean circulation differs considerably between the two hemispheres. That the equivalent extent seasonal cycle changes similarly in both hemispheres is evidence that snow cover and ocean circulation 


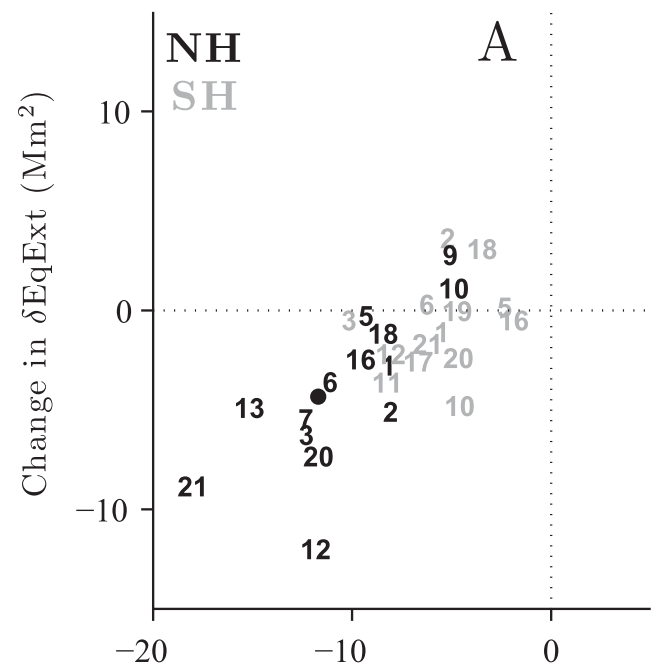

Change in Ann Mean EqExt $\left(\mathrm{Mm}^{2}\right)$

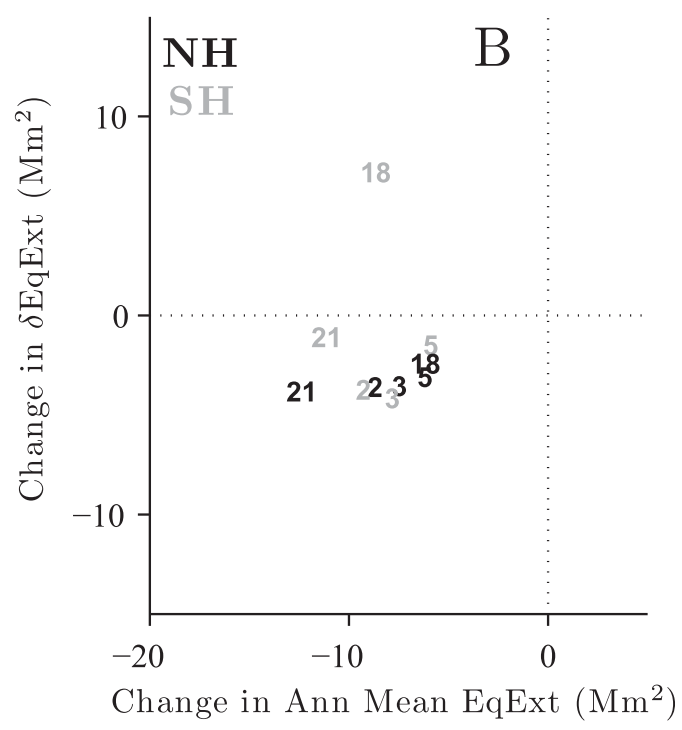

FIG. 7. Influence of edge effects and ocean dynamics on robustness among models. (a) As in Fig. 6 except that, for each hemisphere, models with ice extent less than $0.1 \mathrm{Mm}^{2}$ at any time during 1900-2100 are excluded. (b) As in Fig. 6 , but considering atmosphere-only equilibrium climate sensitivity simulations rather than coupled atmosphereocean transient simulations (see appendix B). Here, the differences between the climate under doubled $\mathrm{CO}_{2}$ and the control simulation are plotted.

are not dominant factors. Third, five CMIP3 GCMs reported sea ice changes in equilibrium simulations of carbon dioxide $\left(\mathrm{CO}_{2}\right)$ doubling that did not include a dynamic ocean (see appendix B). The results of these simulations are plotted in Fig. 7b. Similar to Fig. 6, most of the points lie in the lower quadrant. This demonstrates that the amplitude of the equivalent extent seasonal cycle decreases in response to global warming in both hemispheres in most of these GCMs even in the absence of changes in ocean heat flux convergence. Fourth, the sea ice changes are robust among the models despite substantial intermodel differences in simulated clouds, which implies that clouds do not play a role in this response. Hence the mechanism behind this robust sea ice response is not expected to involve ice motion, snow, ocean circulation, or clouds, and it is expected to be fundamental enough to dominate over intermodel and interhemispheric differences in these quantities. Taken together, these results suggest that the thermodynamic interaction between sea ice and atmospheric processes is a likely source of the changes in the sea ice seasonal cycle. We will address the mechanisms involved in a forthcoming paper.

In summary, the year-to-year retreat of Northern Hemisphere sea ice extent is faster in summer than in winter in observations and GCM projections. The year-to-year retreat of Southern Hemisphere sea ice extent, by contrast, is fastest in winter in GCM projections. The results presented here show that, after accounting for landmasses that rim the Arctic Ocean, the changes in the sea ice cover in both hemispheres are consistent with ice retreat being fastest in winter in the absence of land. This diminished amplitude in the seasonal cycle of sea ice cover in response to warming is robust among the range of GCMs and is uniform in both hemispheres.

Acknowledgments. This work was supported by a TPF Postdoctoral Fellowship through the Caltech Division of Geological and Planetary Sciences, a NOAA Climate and Global Change Postdoctoral Fellowship administered by the University Corporation for Atmospheric Research, a David and Lucile Packard Fellowship, and the Davidow Discovery Fund. We thank the modeling groups and the Program for Climate Model Diagnosis and Intercomparison for making available the CMIP3 multimodel dataset.

\section{APPENDIX A}

\section{Satellite-Derived Observations}

\section{a. Data processing}

Monthly-mean sea ice extent observations in both hemispheres are derived from passive microwave satellite measurements during January 1979-December 2009 (Fetterer et al. 2002). Months with missing values (in both hemispheres, December 1987 and January 1988) are filled with linear interpolation between the same month in the previous year and following year. We use the National Snow and Ice Data Center land mask 
associated with sea ice concentrations from these satellite measurements to compute sea ice equivalent extent.

The curves in Fig. 1a represent the mean 1979-2000 seasonal cycle in daily sea ice extent from the same satellite measurements (Cavalieri et al. 1996). Missing values are filled using linear interpolation from the previous day to the following day. Daily equivalent extent in Fig. $1 \mathrm{~b}$ is computed from extent as described in section 2.

\section{b. Statistical significance in the Southern Hemisphere}

The annual-mean sea ice extent in the Southern Hemisphere increases during 1979-2009 with a linear trend of $0.15 \mathrm{Mm}^{2}$ decade $^{-1}$, or $1.2 \%$ decade $^{-1}$ when scaled by the 1979-2000 mean. This trend is significant at $p<0.003$ (i.e., white noise would produce a trend this far from zero less than $0.3 \%$ of the time). The trend in the amplitude of the ice extent seasonal cycle as a function of time, however, is not distinguishable from zero. The same applies for the trend in the yearly ice extent seasonal cycle amplitude versus yearly annual-mean ice extent, as well as the trend in the 5-yr averages of these quantities (red points in Fig. 2f).

\section{APPENDIX B}

\section{Climate Models}

\section{a. Coupled atmosphere-ocean simulations}

We include in this analysis 21 of the 24 coupled atmosphere-ocean GCMs that participated in CMIP3, excluding two [Goddard Institute for Space Studies Model E-H (GISS EH) and National Center for Atmospheric Research Parallel Climate Model (PCM)] that have not reported sea ice concentration fields to the CMIP3 archive for the simulations we analyze and one [State Key Laboratory of Numerical Modeling for Atmospheric Sciences and Geophysical Fluid Dynamics Flexible Global Ocean-Atmosphere-Land System Model gridpoint version 1.0 (LASG FGOALS-g1.0)] that has a known bias toward vast overestimation of sea ice extent and is typically excluded from sea ice analyses (e.g., Zhang and Walsh 2006). For each model, ice extent during 19002100 is calculated as the total area of grid boxes with at least $15 \%$ sea ice concentration in the "Climate of the 20th Century" simulation, and ice extent during 20002100 is calculated in the same way from the Special Report on Emissions Scenarios (SRES) A1B simulation. When multiple ensemble members are available, we consider only the first member.

Land masks for computing equivalent extent in each GCM are obtained using one of several techniques. For many of the GCMs, land grid boxes are reported as missing values in the sea ice concentration field. For
GCMs that instead reported land grid boxes as having zero sea ice concentration, we use either missing values in the sea surface temperature field reported by the ocean component or nonzero values in the land area fraction reported by the atmosphere component (which always had values of either 0 or 1 for these models), depending on whether the sea ice component in each GCM shares its grid with the ocean or the atmosphere.

\section{b. Atmosphere-only simulations}

We also consider atmosphere-only simulations above a slab ocean with specified ocean heat flux convergence (i.e., ocean "q-flux"). Sea ice concentration for these simulations was reported to the CMIP3 archive by 5 of the 24 GCMs. To assess the change in the sea ice cover in response to $\mathrm{CO}_{2}$ doubling, we calculate the time series of sea ice extent from the "slab ocean control" simulation and the " $2 \mathrm{xCO} 2$ equilibrium" simulation, and then we compute the mean ice extent seasonal cycle during the final $20 \mathrm{yr}$ of each simulation. Note that the Hadley Centre Global Environmental Model version 1 (HadGEM1) becomes seasonally ice free in both hemispheres in the $2 \mathrm{xCO} 2$ equilibrium simulation but that none of the other four GCMs simulates less than $0.1 \mathrm{Mm}^{2}$ of ice extent in either hemisphere.

Land masks in the slab ocean simulations are identical to the coupled simulations from the same GCM with the exception of HadGEM1, in which the sea ice concentration is reported on the atmosphere grid in the former but on the ocean grid in the latter.

\section{APPENDIX C}

\section{Sea Ice Sensitivity}

The sea ice extent sensitivity for each model (Fig. 3b) is computed using a total least squares regression of annual-mean hemispheric sea ice extent on annual-mean global-mean temperature following the methodology in Winton (2011). The observed temperatures are from the GISS surface temperature (GISTEMP) combined land-ocean dataset. The GCMs typically show an approximately linear relationship between ice area and temperature (Gregory et al. 2002; Winton 2011); that is, the sea ice sensitivity is typically constant in time. We use the full 1900-2100 time range for the GCMs and the shorter 1979-2009 time range for the observations.

\section{REFERENCES}

Arzel, O., T. Fichefet, and H. Goosse, 2006: Sea ice evolution over the 20th and 21st centuries as simulated by current AOGCMs. Ocean Modell., 12, 401-415. 
Boe, J. L., A. Hall, and X. Qu, 2009: September sea-ice cover in the Arctic Ocean projected to vanish by 2100 . Nat. Geosci., 2 , 341-343.

Cavalieri, D., C. Parkinson, P. Gloerson, and H. Zwally, 1996, updated 2008: Sea ice concentrations from Nimbus-7 SMMR and DMSP SSM/I passive microwave data, 1978-2007. National Snow and Ice Data Center, digital media. [Available online at http://nsidc.org/data/nsidc-0051.html.]

Comiso, J. C., 2002: A rapidly declining perennial sea ice cover in the arctic. Geophys. Res. Lett., 29, 1956, doi:10.1029/ 2002GL015650.

_ , and F. Nishio, 2008: Trends in the sea ice cover using enhanced and compatible AMSR-E, SSM/I, and SMMR data. J. Geophys. Res., 113, C02S07, doi:10.1029/2007JC004257.

DeWeaver, E., 2007: Uncertainty in climate model projections of Arctic sea ice decline: An evaluation relevant to polar bears. U.S. Geological Survey Admin. Rep., 40 pp. [Available online at http://www.usgs.gov/newsroom/special/polar_bears/docs/ USGS_PolarBear_DeWeaver_GCM-Uncertainty.pdf.]

Dieckmann, G. S., and H. H. Hellmer, 2010: The importance of sea ice: An overview. Sea Ice, 2nd ed. D. N. Thomas and G. S. Dieckmann, Eds., Wiley-Blackwell, 1-22.

Eisenman, I., 2010: Geographic muting of changes in the Arctic sea ice cover. Geophys. Res. Lett., 37, L16501, doi:10.1029/ 2010 GL043741.

Fetterer, F., K. Knowles, W. Meier, and M. Savoie, 2002, updated 2010: Sea ice index. National Snow and Ice Data Center, digital media. [Available online at http://nsidc.org/data/ seaice_index/archives/.]

Francis, J. A., and E. Hunter, 2007: Drivers of declining sea ice in the Arctic winter: A tale of two seas. Geophys. Res. Lett., 34, L17503, doi:10.1029/2007GL030995.

Gregory, J. M., P. A. Stott, D. J. Cresswell, N. A. Rayner, C. Gordon, and D. M. H. Sexton, 2002: Recent and future changes in Arctic sea ice simulated by the HadCM3 AOGCM. Geophys. Res. Lett., 29, 2175, doi:10.1029/2001GL014575.

Kwok, R., G. F. Cunningham, M. Wensnahan, I. Rigor, H. J. Zwally, and D. Yi, 2009: Thinning and volume loss of the Arctic Ocean sea ice cover: 2003-2008. J. Geophys. Res., 114, C07005,doi:10.1029/2009JC005312.

Lindsay, R. W., and J. Zhang, 2005: The thinning of Arctic sea ice, 19882003: Have we passed a tipping point? J. Climate, 18, 4879-4894.

Meier, W., J. Stroeve, F. Fetterer, and K. Knowles, 2005: Reductions in Arctic sea ice cover no longer limited to summer. Eos, Trans. Amer. Geophys. Union, 86, 326.

Nghiem, S. V., I. G. Rigor, D. K. Perovich, P. Clemente-Colón, J. W. Weatherly, and G. Neumann, 2007: Rapid reduction of Arctic perennial sea ice. Geophys. Res. Lett., 34, L19504, doi:10.1029/2007GL031138.

Ogi, M., K. Yamazaki, and J. M. Wallace, 2010: Influence of winter and summer surface wind anomalies on summer Arctic sea ice extent. Geophys. Res. Lett., 37, L07701, doi:10.1029/ 2009GL042356.

Parkinson, C. L., and D. J. Cavalieri, 2008: Arctic sea ice variability and trends, 1979-2006. J. Geophys. Res., 113, C07003, doi:10.1029/2007JC004558.

Perovich, D. K., B. Light, H. Eicken, K. F. Jones, K. Runciman, and S. V. Nghiem, 2007: Increasing solar heating of the Arctic Ocean and adjacent seas, 1979-2005: Attribution and role in the ice-albedo feedback. Geophys. Res. Lett., 34, L19505, doi:10.1029/2007GL031480.

, R. Kowk, W. Meier, S. Nghiem, and J. Richter-Menge, 2009: Sea ice cover. Arctic Report Card 2009. Arctic Council, 9-13. [Available online at http://www.arctic.noaa.gov/report09/ ArcticReportCard_full_report.pdf.]

Petrich, C., and H. Eicken, 2010: Growth, structure and properties of sea ice. Sea Ice, 2nd ed. D. N. Thomas and G. S. Dieckmann, Eds., Wiley-Blackwell, 23-77.

Rigor, I. G., and J. M. Wallace, 2004: Variations in the age of Arctic sea-ice and summer sea-ice extent. Geophys. Res. Lett., 31, L09401, doi:10.1029/2004GL019492.

- - — Arctic Oscillation. J. Climate, 15, 2648-2663.

Serreze, M. C., M. M. Holland, and J. Stroeve, 2007: Perspectives on the Arctic's shrinking sea-ice cover. Science, 315, 1533-1536.

Shimada, K., T. Kamoshida, M. Itoh, S. Nishino, E. Carmack, F. McLaughlin, S. Zimmermann, and A. Proshutinsky, 2006: Pacific Ocean inflow: Influence on catastrophic reduction of sea ice cover in the Arctic ocean. Geophys. Res. Lett., 33, L08605, doi:10.1029/2005GL025624.

Solomon, S., D. Qin, M. Manning, Z. Chen, M. Marquis, K. Averytand, M. Tignor, and H. Miller, Eds., 2007: Climate Change 2007: The Physical Science Basis. Cambridge University Press, 996 pp.

Son, S. W., and Coauthors, 2008: The impact of stratospheric ozone recovery on the Southern Hemisphere westerly jet. Science, 320, 1486-1489.

Stroeve, J., M. M. Holland, W. Meier, T. Scambos, and M. Serreze, 2007: Arctic sea ice decline: Faster than forecast. Geophys. Res. Lett., 34, L09501, doi:10.1029/2007GL029703.

Turner, J., and Coauthors, 2009: Non-annular atmospheric circulation change induced by stratospheric ozone depletion and its role in the recent increase of Antarctic sea ice extent. Geophys. Res. Lett., 36, L08502, doi:10.1029/2009GL037524.

Wang, M. Y., and J. E. Overland, 2009: A sea ice free summer Arctic within 30 years? Geophys. Res. Lett., 36, L07502, doi:10.1029/2009GL037820.

Winton, M., 2011: Do climate models underestimate the sensitivity of Northern Hemisphere sea ice cover? J. Climate, 24, 39243934.

Zhang, X. D., and J. E. Walsh, 2006: Toward a seasonally icecovered Arctic Ocean: Scenarios from the IPCC AR4 model simulations. J. Climate, 19, 1730-1747. 